\title{
Comparative analysis of the Spirulina platensis subcellular proteome in response to low- and high-temperature stresses: uncovering cross-talk of signaling components
}

\author{
Pavinee Kurdrid ${ }^{1 \dagger}$, Jittisak Senachak ${ }^{1 \dagger}$, Matura Sirijuntarut ${ }^{3}$, Rayakorn Yutthanasirikul ${ }^{3}$, \\ Phuttawadee Phuengcharoen ${ }^{3}$, Wattana Jeamton ${ }^{3}$, Sittiruk Roytrakul', Supapon Cheevadhanarak ${ }^{2}$ and \\ Apiradee Hongsthong ${ }^{1 *}$
}

\begin{abstract}
The present study focused on comparative proteome analyses of low- and high-temperature stresses and potential protein-protein interaction networks, constructed by using a bioinformatics approach, in response to both stress conditions.

The data revealed two important points: first, the results indicate that low-temperature stress is tightly linked with oxidative stress as well as photosynthesis; however, no specific mechanism is revealed in the case of the hightemperature stress response. Second, temperature stress was revealed to be linked with nitrogen and ammonia assimilation. Moreover, the data also highlighted the cross-talk of signaling pathways. Some of the detected signaling proteins, e.g., Hik14, Hik26 and Hik28, have potential interactions with differentially expressed proteins identified in both temperature stress conditions. Some differentially expressed proteins found in the Spirulina protein-protein interaction network were also examined for their physical interactions by a yeast two hybrid system $(\mathrm{Y} 2 \mathrm{H})$. The $\mathrm{Y} 2 \mathrm{H}$ results obtained in this study suggests that the potential PPI network gives quite reliable potential interactions for Spirulina. Therefore, the bioinformatics approach employed in this study helps in the analysis of phenomena where proteome analyses of knockout mutants have not been carried out to directly examine for specificity or cross-talk of signaling components.
\end{abstract}

\section{Introduction}

Under thermal stress conditions, cells undergo many cellular modifications in order to survive and grow. These modifications are generated by a network of genes that are up- or down-regulated either simultaneously or in cascade. Among the well-known mechanisms related to temperature stress, maintenance of the homeoviscous adaptation of the cell membrane in order to retain the proper membrane flexibility is well defined.

Spirulina cells encounter temperature fluctuations, associated with outdoor mass cultivation, that have a

\footnotetext{
* Correspondence: apiradee@biotec.or.th

† Contributed equally

'BEC Unit, National Center for Genetic Engineering and Biotechnology, 49

Soi Theintalay 25, Thakham, Bangkhuntien, Bangkok, 10150, Thailand
}

Full list of author information is available at the end of the article relevant effect on biomass yield and the biochemical content of the cells. Some components with pharmaceutical benefits, such as unsaturated fatty acids in membrane lipids, have been shown to play vital roles in the response to temperature change. In addition, an association between fatty acid desaturation and temperature stress has been well established [1].

Physiological changes to the fatty acid content of the cytoplasmic membrane are also observed in Spirulina platensis. In comparison with cells maintained at the ideal growth temperature $\left(35^{\circ} \mathrm{C}\right), S$. platensis cells synthesize up to $23 \%$ more $\gamma$-linolenic acid (GLA; $\left.\mathrm{C} 18: 3^{\Delta 9,12,6}\right)$ after a temperature downshift $\left(22^{\circ} \mathrm{C}\right)$, whereas the GLA level decreases approximately $30 \%$ upon a temperature increase $\left(40^{\circ} \mathrm{C}\right)$ [2]. Therefore, extensive studies on the expression and regulation of 
desaturase genes in response to temperature changes have been performed by using a gene-by-gene approach [3].

High-throughput approaches such as proteomics have also been applied to analyze the temperature response of Spirulina. The proteomic analyses of the low- and high-temperature responses in Spirulina were performed by our research group using two-dimensional differential gel electrophoresis (2D-DIGE) coupled with protein identification by mass spectrometry [4]. As a result of the analysis of differential expression, four groups of proteins were found to be in common between Spirulina cells under both temperature stress conditions: (i) signal transduction proteins, (ii) chaperones, (iii) stressrelated proteins and (iv) proteins related to DNA modification \& repair $[4,5]$. Moreover, two groups of proteins, classified as channeling \& secretion and photosynthesis, were detected as differentially expressed proteins only under low-temperature stress [4]. It is obvious that stress response mechanisms, when considered in isolation from other stresses in order to simplify interpretation, might not be comprehensive. Thus, it should be beneficial to understand a large part of the temperature stress response of Spirulina because temperature is an important environmental factor for the fatty acid contents in the cells, as mentioned above.

However, one limitation of the gel-based technique is that some differentially expressed proteins, such as those with an extreme pI or extreme molecular weight, cannot be detected. Thus, an aim of the present study was to perform a proteomic analysis of Spirulina in response to temperature reduction using iTRAQ-multidimensional liquid chromatography and tandem mass spectrometry. Moreover, the focus of the study was on comparative proteome analyses of low- and high-temperature stresses, as well as potential protein-protein interaction networks, constructed by using a bioinformatics approach, that respond to both stress conditions.

\section{Materials and methods}

\section{Culture Conditions and Low-Temperature Exposure}

Cultures of axenic S. platensis, strain $\mathrm{C}$, were grown at their optimal temperature, $35^{\circ} \mathrm{C}$, under illumination by $100 \mu \mathrm{Em}^{-2} \mathrm{~s}^{-1}$ fluorescent light with continuous stirring in $2 \mathrm{~L}$ of Zarrouk's medium [6]. For the low-temperature exposure, the culture was grown until the optical density at $560 \mathrm{~nm}$ reached 0.4 (mid-log phase), at which time a cell sample was harvested by filtration before shifting the growth temperature $(\mathrm{t}=0 \mathrm{~min})$. The growth temperature was immediately shifted from $35^{\circ} \mathrm{C}$ to $22^{\circ} \mathrm{C}$, and the culture was incubated for 45,90 or $180 \mathrm{~min}$ before cell harvesting (Figure 1a). It should be noted that the experiment was carried out in the same manner for high temperature $\left(40^{\circ} \mathrm{C}\right)$ exposure [5]. However, in

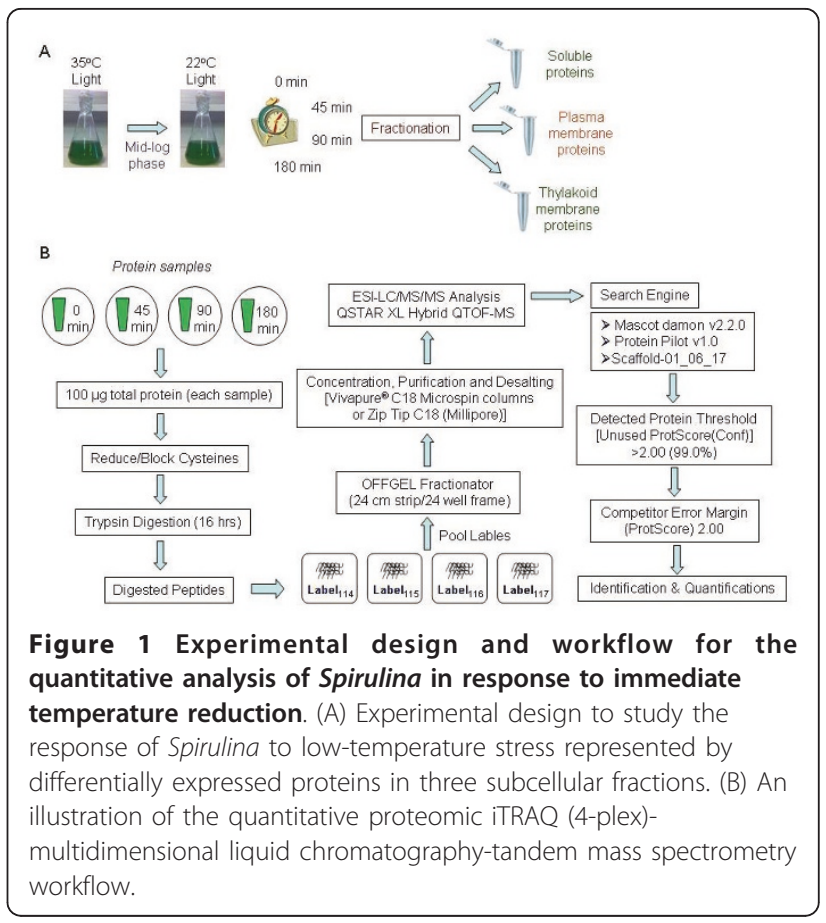

the present study, only the low temperature exposure samples were subjected to the iTRAQ-multidimensional liquid chromatography and tandem mass spectrometry.

\section{Preparation of Subcellular Fractions, Protein Extraction and Protein Quantification}

The harvested cells were washed and then lysed using a French press at $700 \mathrm{psi}$, and the soluble protein fraction was collected. The plasma and thylakoid membranes were isolated on a sucrose gradient as described by Murata and Omata [7]. The washed membrane pellet was resuspended in the dissolving buffer containing $2 \mathrm{M}$ thiourea, $8 \mathrm{M}$ urea, $20 \mathrm{mM}$ Tris, $30 \mathrm{mM}$ DTT, $1 \%$ (v/v) IPG buffer, $0.05 \%(\mathrm{w} / \mathrm{v}) \beta$-dodecyl maltoside, and $4 \%$ $(w / v)$ CHAPS [4]. For each of the time periods for each of the subcellular fractions, $100 \mu \mathrm{g}$ of protein was precipitated in a $1: 6$ volume of acetone overnight at $-20^{\circ} \mathrm{C}$ and resuspended in the appropriate buffers for iTRAQ labeling.

\section{Four-Plex Isobaric Tag Peptide (iTRAQ) Labeling}

Protein concentration of each sample was measured before subjected to iTRAQ labeling. For each of the time periods for each of the subcellular fractions, $100 \mu \mathrm{g}$ of protein was reduced and alkylated as described by the manufacturer's protocol (Applied Biosystems, USA). Subsequently, the protein samples were digested with trypsin (Promega, USA) (1:5) overnight at $37^{\circ} \mathrm{C}$. Peptide samples from the four time periods $(0,45,90$ and 180 min) were then labeled with 4-plex iTRAQ $(114,115$, 
116 and 117, respectively) using an iTRAQ labeling kit (Applied Biosystems) according to the manufacturer's protocol. The subcellular fractions from all time periods were combined, vacuum evaporated and stored at $-20^{\circ} \mathrm{C}$ prior to separation by liquid chromatography.

\section{Liquid Chromatography and Tandem Mass Spectrometry}

The workflow of the experiment is shown in Figure 1b. Off-gel fractionation (Agilent, USA) with a buffer of $\mathrm{pH}$ 3-10 was performed to increase the sensitivity of the protein analysis, according to the manufacturer's protocol. After the twenty-four off-gel fractions were cleaned using ZipTips ${ }^{\circledR}$ (Millipore, USA), the samples were subjected to liquid chromatography-tandem mass spectrometry (LC-MS/MS) using a Famos-Switchos-Ultimate nano-LC system (Dionex, LC packing, The Netherlands) interfaced with a QSTAR XL (Applied Biosystems; MDS-Sciex) tandem ESI-QUAD-TOF MS. Concentrated off-gel fractions were resuspended in $0.1 \%$ formic acid, injected and captured in a $0.3 \times 5 \mathrm{~mm} \mathrm{C} 18$ trapping cartridge (LC Packings). The trapped peptides were eluted onto a $0.075 \times 100 \mathrm{~mm} \mathrm{C18}$ analytical column (packed in-house with 5 - $\mu \mathrm{m}$ particle size packing material from Column Engineering, USA), using an automated binary gradient with a flow of $100 \mathrm{nl} / \mathrm{min}$ across a $0 \%$ to $90 \%$ acetonitrile gradient in $0.1 \%$ formic acid over a 110 -min period. The eluted peptides were separated through the column and then analyzed online by tandem mass spectrometry.

Eluted peptides from the LC column were sprayed directly into the orifice of the mass spectrometer, which was run in IDA (information dependent acquisition) mode, selecting all $2+$ to $3+$ charged ions with a signal intensity greater than eight counts per second over the specified mass range. For experimental run 1, all fractions were run and scanned in the $\mathrm{m} / \mathrm{z}$ range of 300 $1800 \mathrm{amu}$. For run 2, all fractions were run and scanned in the $\mathrm{m} / \mathrm{z}$ range of $100-1800 \mathrm{amu}$, with an exclusion list derived from the previously identified peptides. Further details on the MS/MS conditions are described elsewhere [8]. Three subcellular fractions obtained from three independent experiments (low-temperature stress) were analyzed.

\section{Proteomic Data Analysis}

The quantification analysis of iTRAQ-peptide spectra was performed using ProteinPilot ${ }^{\mathrm{TM}}$ software v. 1.0 (Applied Biosystems) and Scaffold software v. 1.7 (Proteome Software, Inc.). However, the S. platensis strain C1 genome database was not available in the database connected to ProteinPilot ${ }^{\mathrm{TM}}$ and Scaffold software. Result files of the three subcellular fractions obtained by using ProteinPilot ${ }^{\mathrm{TM}}$ were shown as Additional file 1, 2, 3 Table S1a, S1b, S1c. Thus, protein identifications were carried out further by converting the raw data files (*.wiff) to *.mzXML and then to ".mgf files, consecutively, followed by a search against an in-house S. platensis C1 protein database (6360 ORFs, accessed March 2009, unpublished database) using the Mascot Search algorithm. However, the open reading frame (orf) code of the published genome of Synechocystis that matched the designated Spirulinaorf was also reported. The quantification and identification data were integrated using Microsoft Access. The significant differentially expressed proteins were filtered by the same criteria as that of the 2D-DIGE experiment [4,5], $p$-value $\leq 0.05$ and fold change (log scale) $\geq 1.5$ (for up-regulated proteins) or $\leq-1.5$ (for down-regulated proteins). Moreover, the criteria for protein ID was sequence similarity by matching peptide sequences of each identified protein obtained from LC-MS/MS coupled with ProteinPilot and Scaffold with $S$. platensis strain $\mathrm{C} 1$ protein sequence database, translated from its genome sequence.

\section{Transcriptional Analysis by RT-PCR}

Spirulina RNA isolation was performed as described previously [9]. The expression levels of the gene transcripts of interest were analyzed by RT-PCR. RT-PCR kits were selected according to the size of the gene transcripts. The AccessQuick ${ }^{\mathrm{TM}}$ RT-PCR System (Promega) and the SuperScript III First-Strand Synthesis System coupled with the Platinum ${ }^{\circledR}$ Taq DNA Polymerase High Fidelity kit (Invitrogen, USA) were used for gene sizes ranging from $500 \mathrm{bp}-2 \mathrm{~kb}$ and $2 \mathrm{~kb}-6 \mathrm{~kb}$, respectively, according to the manufacturers' protocols. Details on the primers are shown in Additional file 4 Table S2. Quantification of the RT-PCR products was performed by measuring the densities of the bands using the Image Quant TL program (GE Healthcare Biosciences). Normalization of the RT-PCR product levels was then carried out by comparing the density of the designated band to the density of the $16 \mathrm{~S}$ rRNA bands.

\section{Clustering of Protein Expression Patterns}

The protein expression dataset (obtained by using LCMS/MS technique) was validated for the input wellform of protein ratio values. Then, the null values and ratios that were extremely high or low, relative to the threshold value of $1 \mathrm{e}+-10$, were filtered out. K-mean clustering was applied to obtain three major temporal response patterns, resistance (short-term response only), adaptation (long-term response only) and sustained tolerance (short- and long-term response) patterns. Other proteins, for which expression patterns cannot be clustered into the three majority groups, were clustered separately. A good k-profile 
number was chosen by simulation according to Martin et al. [10].

\section{Potential Protein-Protein Interaction (PPI) Network Construction}

A protein-protein interaction (PPI) network in Spirulina was constructed on the prototype PPI database of Synechocystis [11]. Prototype construction was based on a graph in which nodes and edges represent proteins and interactions, respectively. Each interaction was experimentally identified by a yeast two-hybrid system. An edge was drawn from a bait protein and targeted to its prey protein at the head of the edge. Homologous proteins identified by BLAST similarity searches with significance values less than $1 \times 10^{-10}$ were mapped to their best-hit Synechocystis protein nodes. The connectivity of the overall network was analyzed for maximal connected subgraphs using the concepts of weakly connected components and biconnected components. In each sub-network (connected components), a protein in the most highly connected part was selected, along with the drawn interactions that target its reachable proteins. Those interactions can be seen as a bridge between proteins, which in graph theory are classified as cut vertices. Finally, differentially expressed proteins in Spirulina were mapped to their corresponding nodes. The height of each node represents the level of differential expression.

\section{Protein-Protein Interaction Analysis by Yeast Two Hybrid System (Y2H)}

Y2HGold and Y187 (Clontech, USA) were used for designated plasmid DNA transformation. Testing for bait autoactivation, which leads to false positives, is necessary prior to the experiments. The bait-containing plasmid, Y2HGold, and the prey-containing plasmid, Y187, were mated in $300 \mu \mathrm{l}$ of 2XYPDA broth. In addition, the positive control (plasmid pGBKT7-p53 in Y2HGold mated with plasmid pGADT7-T in Y187) and negative control (plasmid pGBKT7-Lam in Y2HGold mated with plasmid pGADT7-T in Y187) were mated under identical conditions. The yeast mating cultures were incubated at $30^{\circ} \mathrm{C}$, with shaking at $200 \mathrm{rpm}$ for 24 hr. Then, the cultures were spread onto SD/-Leu/-Trp (DDO) and SD/-Leu/-Trp/X- $\alpha$-gal/AbA dropout (DDO/ $\mathrm{X} / \mathrm{A}$ ) plates, and incubated at $30^{\circ} \mathrm{C}$ for 3 days. Subsequently, the blue colonies were picked and streaked onto high stringency SD/-Ade/-His/-Leu/-Trp/X- $\alpha$-gal/ AbA dropout (QDO/X/A) plates, followed by incubation at $30^{\circ} \mathrm{C}$ for 3-5 days. Furthermore, the switching of yeast strains for the bait-containing plasmid and the prey-containing plasmid were done to confirm the specific interaction between bait and prey proteins. Positive results were expected for the specific interaction.

\section{Results}

\section{General overview}

Proteomic analyses of $S$. platensis responding to immediate low- and high-temperature shifts, from $35^{\circ} \mathrm{C}$ to $22^{\circ} \mathrm{C}$ and $40^{\circ} \mathrm{C}$, respectively, were performed by using two approaches, 2D-DIGE (the previous studies $[4,5]$ ) and iTRAQ LC-MS/MS (the present study). The levels of protein expression after 180 min of temperature shift were compared to those of the control cyanobacteria grown at $35^{\circ} \mathrm{C}(0 \mathrm{~min})$. In the present study, 52 proteins were identified as differentially expressed proteins in response to the temperature reduction. Twenty-eight, sixteen and two differentially expressed proteins were revealed in the soluble, thylakoid membrane (TM) and plasma membrane (PM) fractions, respectively, whereas, two proteins were detected in all subcellular fractions, and three proteins were found in soluble and TM fractions [Additional file 5 Table S3]. When the differentially expressed proteins identified by 2 different proteomic techniques, 2D-DIGE (the previous studies $[4,5]$ ) and iTRAQ LC-MS/MS (the present study), were compared, only one protein, GroEL, detected by both techniques was identified; furthermore, 142 and 51 proteins were uniquely detected by 2D-DIGE and LC-MS/ MS, respectively.

When the two stress conditions were compared, a set of 100 proteins, including 3 signaling proteins, was identified as a response to the low-temperature shift, and a set of 69 proteins, including 17 signaling proteins, was identified as a response to the high-temperature shift. Furthermore, a set of 20 proteins, including 3 signaling proteins, was found to be common between the two temperatures [Additional file 6, 7, 8 Table S4a, S4b, S4c].

The three sets of proteins mentioned above were mapped onto a Cyanobase protein-protein interaction (PPI) network to construct a Spirulina potential PPI network [Additional file 9, 10, 11, 12, 13, 14, 15, 16, 17 Figure S1a, S1b, S1c, S1d, S1e, S1f, S1g, S1h, S1i], and potential interactions were tested by using a yeast two hybrid system. Moreover, some proteins of interest were analyzed at the transcriptional level in order to study their regulation [Additional file 18 Figure S2].

\section{Clustering of protein expression patterns}

The clustering of protein expression patterns in response to low-temperature stress was shown in Figure 2, 3, 4, 5, 6, 7, 8, 9, 10, 11 and Additional file 19 Table S5. The expression patterns were classified into 10 clusters. The summary of major protein expression patterns, resistant, adaptation and sustained tolerance, observed after exposure to the low-temperature stress by using LC-MS/MS technique was shown in Table 1. 


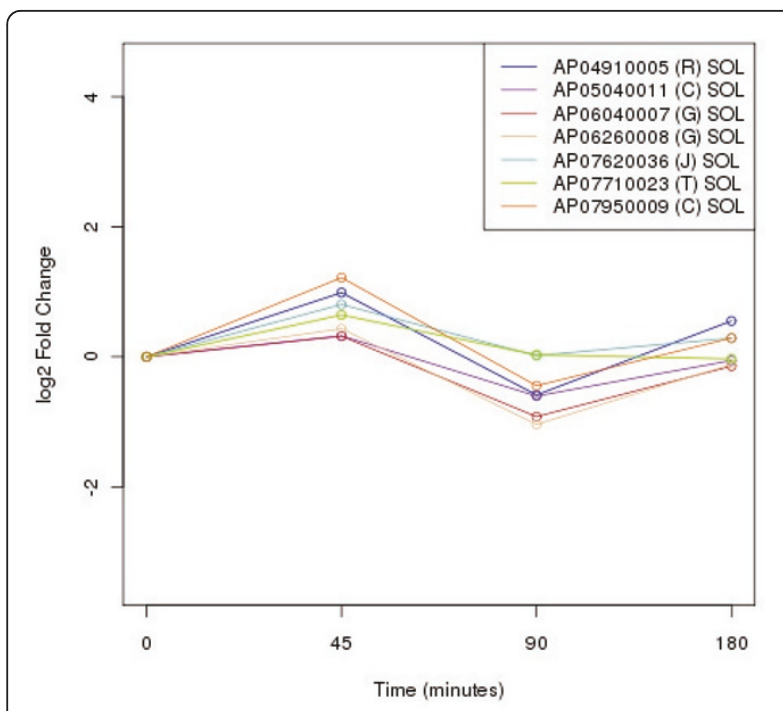

Figure 2 Cluster 1 of expression pattern clustering of the differentially expressed proteins detected by using LC-MS/MS technique after the low-temperature exposure.

\section{Low-temperature responsive proteins}

The three signaling proteins found only under the lowtemperature stress condition are AP07580006, AP06700009 and AP07710023, which are matched with sll0821, sll5060 (or Hik14) and slr0947 of Synechocystis, respectively [Additional file 6 Table S4a].

Besides the signaling proteins, there are 97 proteins that responded to the low-temperature condition, as detected by 2D-DIGE and LC-MS/MS approaches [Additional file 6 Table S4a]. In addition to ATP synthase, chaperones, ribosomal proteins and proteins

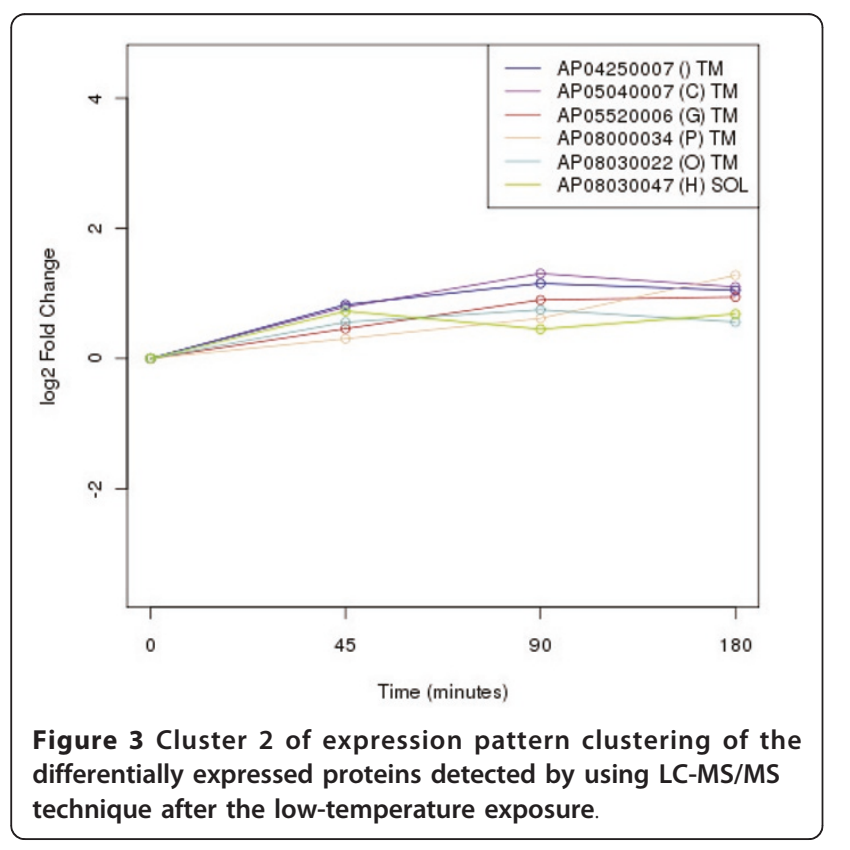

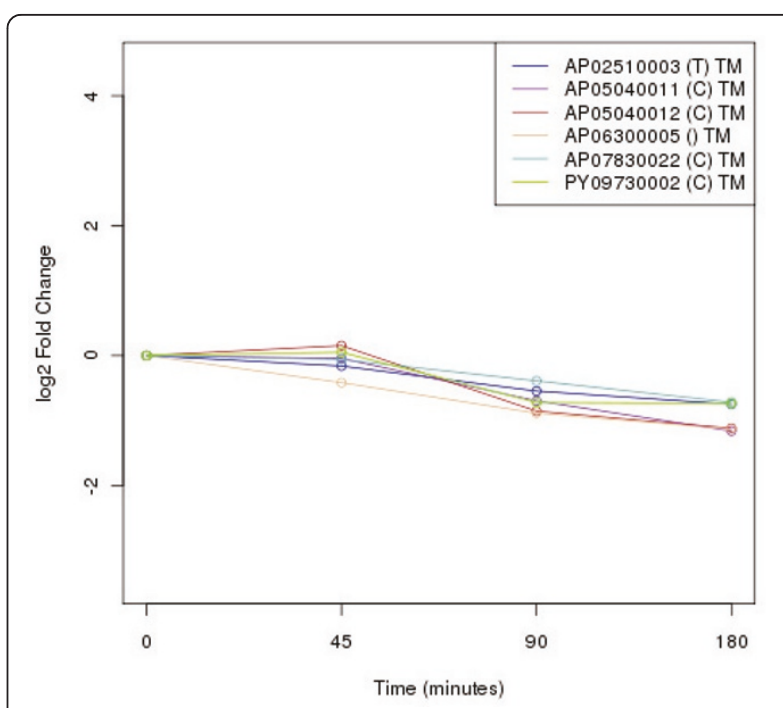

Figure 4 Cluster 3 of expression pattern clustering of the differentially expressed proteins detected by using LC-MS/MS technique after the low-temperature exposure.

associated with post-translational modification, most of the cold-responsive proteins are involved in oxidative stress, nitrogen \& ammonia assimilation and photosynthesis. A well-known oxidative stress-related protein, peroxidase, was up-regulated after the low-temperature exposure; however, other proteins involved in oxidative stress, such as (p)ppGpp synthetase, argininosuccinate synthase and glutamine synthetase, were downregulated.

In the case of proteins related to nitrogen and ammonia assimilation, NADH dehydrogenase (ndh), nitrate

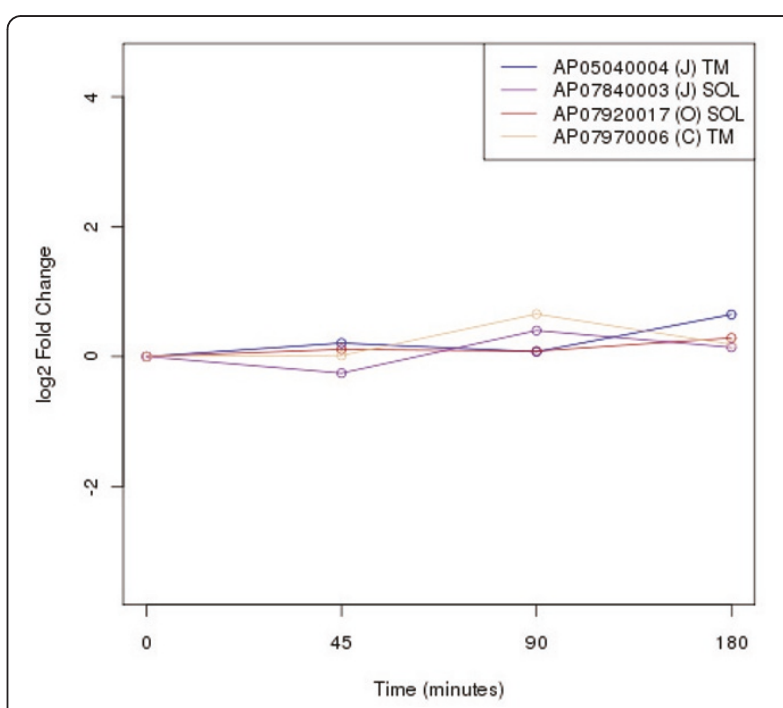

Figure 5 Cluster 4 of expression pattern clustering of the differentially expressed proteins detected by using LC-MS/MS technique after the low-temperature exposure. 


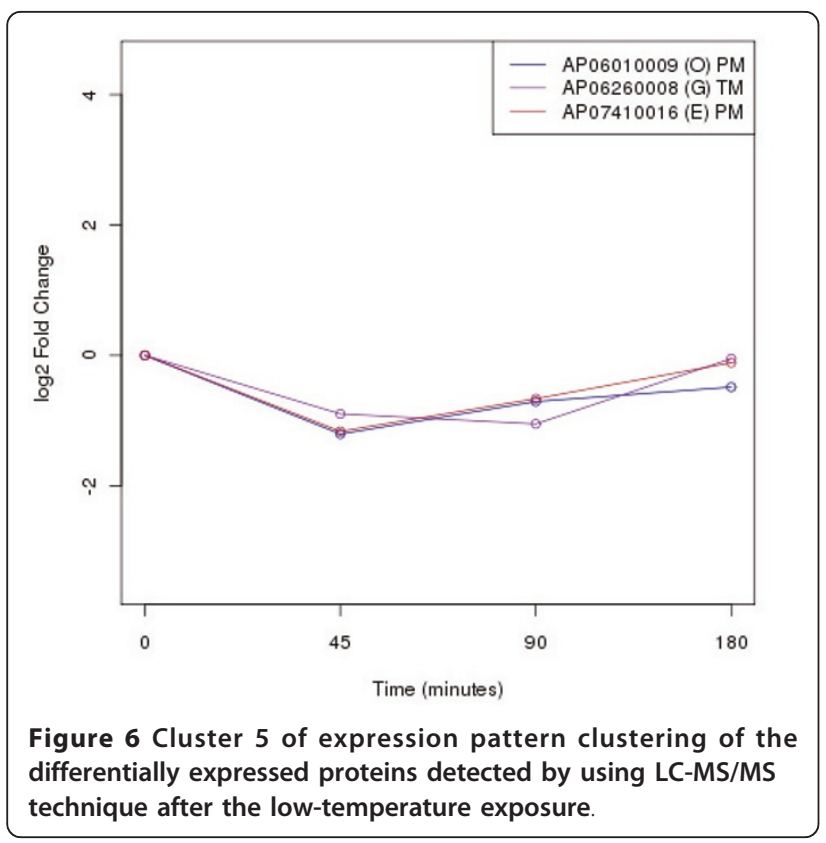

$\mathrm{ABC}$ transporter $(\mathrm{NrtD})$ and PEP carboxylase (Ppc) were differentially expressed. The ndh was up-regulated, whereas the other two were down-regulated [Additional file 6 Table S4a].

Moreover, several photosynthetic proteins were differentially expressed in response to the stress, including uroporphyrinogen decarboxylase (UroD or HemE), magnesium chelatase (ChlI), photochlorophyllide reductase (ChlN), PsaB, PsaF from photosystem I (PSI), PSI assembly protein (Ycf4), Rubisco small subunit (RbcS) and a Rubisco related protein, CcmM [Additional file 6

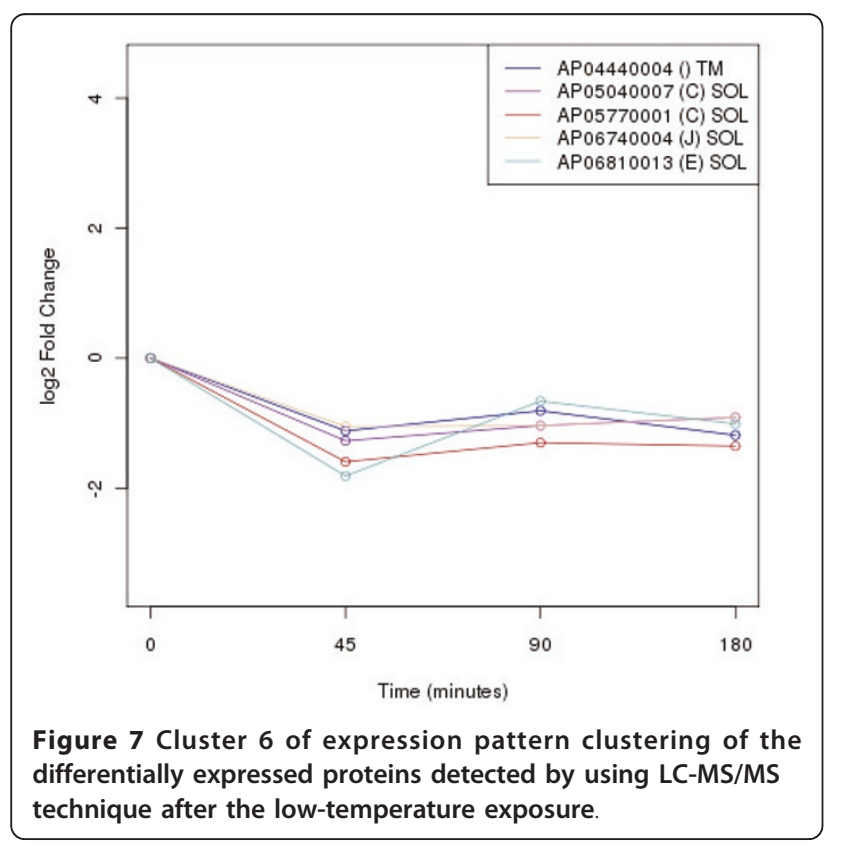

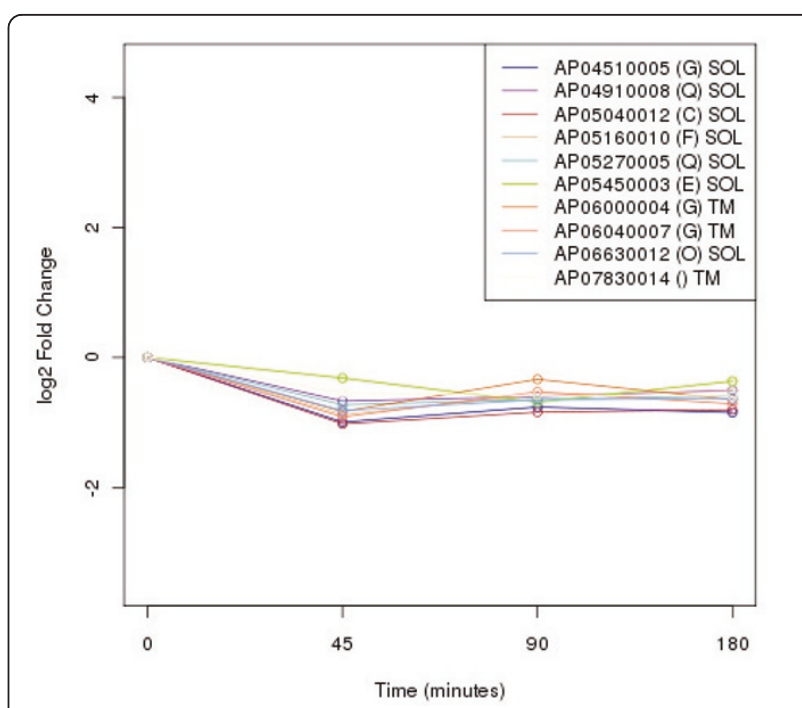

Figure 8 Cluster 7 of expression pattern clustering of the differentially expressed proteins detected by using LC-MS/MS technique after the low-temperature exposure.

Table S4a] [4]. It should be noted that only PsaB was down-regulated, whereas others photosynthetic proteins were up-regulated upon immediate temperature reduction.

We examined the levels at which the expression of the signaling proteins (AP07580006 or Sll0821), HemE, Ppc and Hsp90 were regulated. The mRNA and protein levels of the signaling protein and HemE were correlated, indicating that the proteins are most likely regulated at the transcriptional level [Additional file 18 Figure S2] (Table 2). In contrast, the transcript levels of

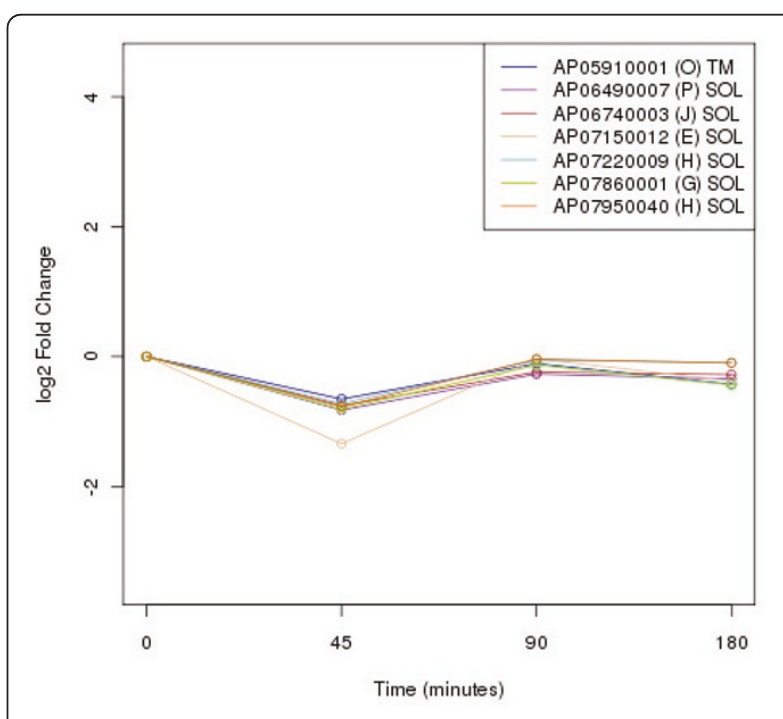

Figure 9 Cluster 8 of expression pattern clustering of the differentially expressed proteins detected by using LC-MS/MS technique after the low-temperature exposure. 


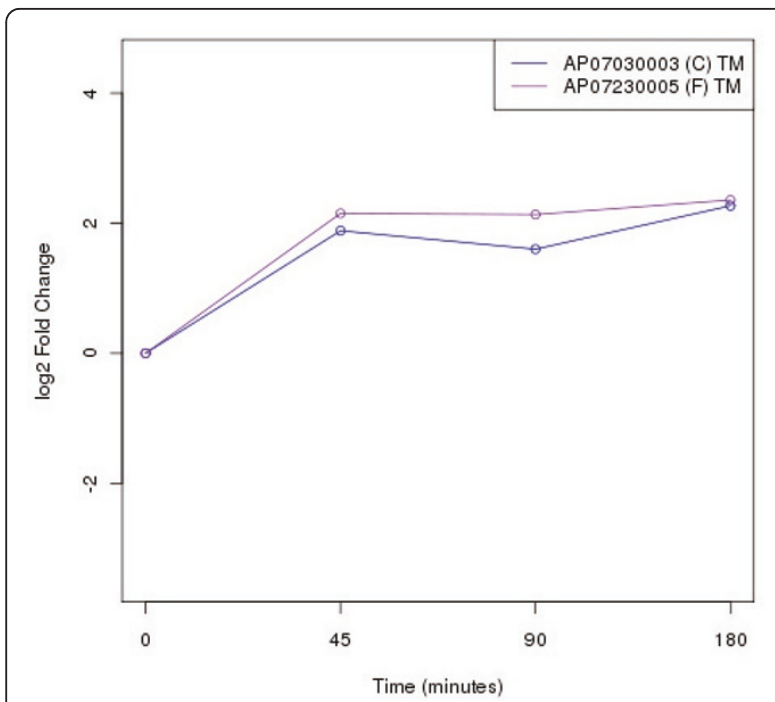

Figure 10 Cluster 9 of expression pattern clustering of the differentially expressed proteins detected by using LC-MS/MS technique after the low-temperature exposure.

Ppc and Hsp90 did not correlate with their protein levels, suggesting that the proteins are possibly regulated at the post-transcriptional or post-translational level [Additional file 18 Figure S2] (Table 2).

\section{High-temperature responsive proteins}

In addition to our previous report [5], as many as seventeen signal transduction proteins were classified as heatresponsive proteins. Fourteen of them were up-regulated and three proteins were down-regulated [Additional file 7 Table S4b]. In addition to signaling and energy

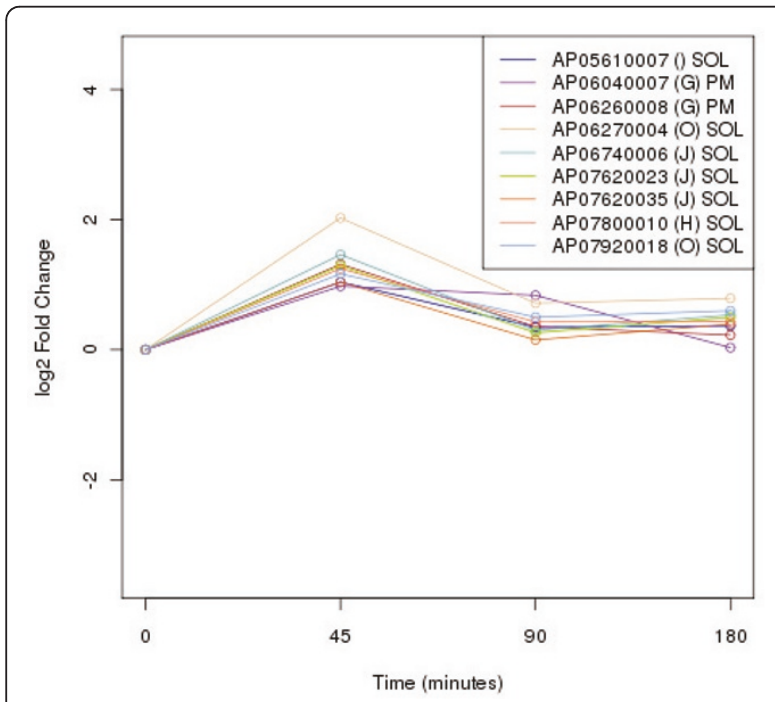

Figure 11 Cluster 10 of expression pattern clustering of the differentially expressed proteins detected by using LC-MS/MS technique after the low-temperature exposure. production related proteins, other groups of proteins found only after temperature elevation were (i) chaperone proteins, e.g., DnaK; (ii) translational proteins, e.g., Rps; (iii) transcriptional regulators, e.g., LysR and Baf; (iv) lipid desaturation proteins, e.g., $\Delta^{9}$ desaturase; and (v) translocation systems, e.g., twin arginine translocation protein.

\section{Proteins in common between the two temperatures}

The three signaling proteins found in common after the exposure to low-and high-temperature stresses are AP04840005, AP07350018 and AP07670017. The latter gene matched with sll0779 of Synechocystis, whereas the first two did not match with any Synechocystis gene [Additional file 8 Table S4c]. In addition to signal transduction proteins, six groups of proteins were identified as common between the two temperature stresses: (i) chaperones, e.g., ClpB and GroEL; (ii) proteins related to nitrogen and ammonia assimilation, e.g. NarB and ferredoxin-dependent glutamate synthase (GltB); (iii) stress-related proteins, e.g., DEAD/DEAH box helicase and S-adenosyl-L-homocysteine (SAH) hydrolase; (iv) post-translational modification, e.g., glycosyl transferase; (v) DNA damage and DNA repairing systems, e.g., exonuclease (SbcC); and (vi) transporters, e.g., ABC transporter [Additional file 8 Table S4c]. It is noteworthy that all the proteins found in common between the two stress conditions were up-regulated.

In case of transcriptional analysis, the transcriptional levels of the two component sensor histidine kinase (AP07670017 or sll0779), GroEL, GltB and DEAD/DEAH box helicase were studied by using RT-PCR. The results showed correlation between the transcript levels and the protein levels, indicating regulation was at the transcriptional level [Additional file 18 Figure S2] (Table 2).

\section{Potential protein-protein interactions}

The three sets of proteins, low-temperature responsive proteins, high-temperature responsive proteins and proteins in common between the two temperatures, mentioned above were mapped onto a Cyanobase proteinprotein interaction (PPI) network to construct a Spirulina potential PPI network [Additional file 9, 10, 11, 12, 13, 14, 15, 16, 17 Figure S1a, S1b, S1c, S1d, S1e, S1f, S1g, S1h, S1i].

\section{PPI analysis by using yeast two hybrid system ( $\mathrm{Y} 2 \mathrm{H})$}

Five pairs of potentially interacting proteins obtained from the potential PPI network were tested for their interactions by using a $\mathrm{Y} 2 \mathrm{H}$ system (Figure 12). The results clearly showed that SigA interacts with ChlN, Ppc and Baf, whereas the cut-vertex two component signaling system (Hik21 or AP07430015) interacted with HemE or UroD. Moreover, the $\mathrm{Y} 2 \mathrm{H}$ also gave a positive 
Table 1 Summary of the major protein expression patterns observed after exposure to the low-temperature stress by using LC-MS/MS technique.

\begin{tabular}{ccc}
\hline Expression pattern & Proteins in trend (\%) & COG-function \\
\hline Short-term only (Resistant) & 27.1 & C, G, H, J, O, R, T \\
Long-term only (Adaptation) & 10.2 & $C$ \\
Short- and long-term (Sustained tolerance) & 55.9 & C, E, F, G, H, J, O, P, Q, R, T \\
Other & 6.8 & C, J, O \\
\hline
\end{tabular}

(Note: COG class; C: Energy production and conversion, E: Amino acid transport and metabolism, F: Nucleotide transport and metabolism, G: Carbohydrate transport and metabolism, $\mathrm{H}$ : Coenzyme transport and metabolism, J: Translation, ribosomal structure and biogenesis, O: Post-translational modification, protein turnover, chaperone functions, P: Inorganic ion transport and metabolism, Q: Secondary metabolites biosynthesis, transport and catabolism, R: General Functional Prediction only, T: Signal transduction mechanisms)

result for PleD (a response regulator/AP07540011) and EfTu.

\section{Discussion}

\section{Clustering of protein expression patterns}

The protein expression pattern clustering detected three clusters, representing resistance, adaptation and sustained tolerance proteins $[5,12]$, in addition to the other pattern. If all differentially expressed proteins in response to low-temperature stress detected by using LC-MS/MS technique are set as $100 \%$, the percentages of the resistance, adaptation and sustained tolerance groups are $27.1 \%, 10.2 \%$ and $55.9 \%$ respectively. The results shown in Figure 2, 3, 4, 5, 6, 7, 8, 9, 10, 11 and Table 1 demonstrate that the majority of proteins belong to the sustained tolerance expression pattern, which is similar to that of the high-temperature stress response reported earlier by our group [5].

It is noteworthy that the energy production and conversion related proteins in the group of ATPase and photosystem I \& II detected in the thylakoid membrane fraction are the only members of the adaptation group (Table 1) [Additional file 19 Table S5].

\section{Low-temperature responsive proteins and their potential PPI}

According to the potential PPI network, a low-temperature responsive signaling protein, AP07580006 interacts with several hypothetical proteins, ferrochelatase (HemH), and two response regulators that contain a CheY-like receiver and GGDEF domains (Figure 13). In contrast, no potential interaction was found for AP07710023 signaling proteins. However, AP06700009 or Hik14 associated with SigG, which interacted with RpoDI or SigA, the expression level of which was up-regulated about 1.46 fold (a bit less than the cut-off at 1.5 fold) under low-temperature stress [Additional file 9 Figure S1a]. Interestingly, SigA itself interacts with the photosynthetic protein ChlN, as well as proteins associated with nitrogen and ammonia assimilation: Ppc, nitrate reductase (NarB) (found as a common up-regulated protein under low- and high-temperature stress), a nitrate regulatory protein $(\mathrm{G} \ln B)$ and a transcription regulator (Baf; up-regulated under temperature elevation) (Figure 14). It should be noted that $G \ln B$ was 1.36 fold significantly down-regulated (9\% less than the cut-off level). Furthermore, it should be noted that SigA also associates with another signal protein, Hik25 (AP08040015), whose expression level did not vary after exposure to the temperature stress [Additional file 9 Figure S1a].

Furthermore, the photosynthetic proteins that responded to the low-temperature stress are also associated with other cell processes. For example, the potential PPI indicated that HemE was associated with the cut-vertex two-component system, AP07430015 (slr2098 or Hik21) (Figure 15). ChlI has been reported to be

Table 2 Regulation levels of several differentially expressed proteins of interest in response to temperature changes.

\begin{tabular}{ccccc}
\hline ORF & Protein name & Regulation level & Localization & Detected condition \\
\hline AP05380002 & DEAD/DEAH box helicase domain protein (membrane helicase) & Transcriptional level & PM, SOL, TM & Common \\
AP06740013 & Ferredoxin-glutamate synthase & Transcriptional level & PM, SOL, TM & Common \\
AP06900013 & Uroporphyrinogen decarboxylase & Transcriptional level & TM & Low-temperature \\
AP07580006 & Response regulator (CheY like-GGDEF containing protein) & Transcriptional level & PM & Low-temperature \\
AP07670017 & Two-component sensor histidine kinase & Transcriptional level & PM, SOL & Common \\
AP08030020 & Heat shock protein 90 (Hsp90) & PTC or PTL or EA & TM & Low-temperature \\
AP08030057 & Phosphoenolpyruvate carboxylase & PTC or PTL or EA & SOL & Low-temperature \\
AP08040017 & Chaperone GroEL & Transcriptional level & SOL, TM & Common \\
\hline
\end{tabular}

*PTC, PTL and EA represent post-transcriptional level, post-translational level and enzymatic activity level, respectively.

Note: The figures that represent mRNA levels and protein levels of the proteins of interest shown in this table were Additional file 10 Figure S2. PM, SOL and TM represent plasma membrane, soluble, and thylakoid membrane fractions, respectively. 

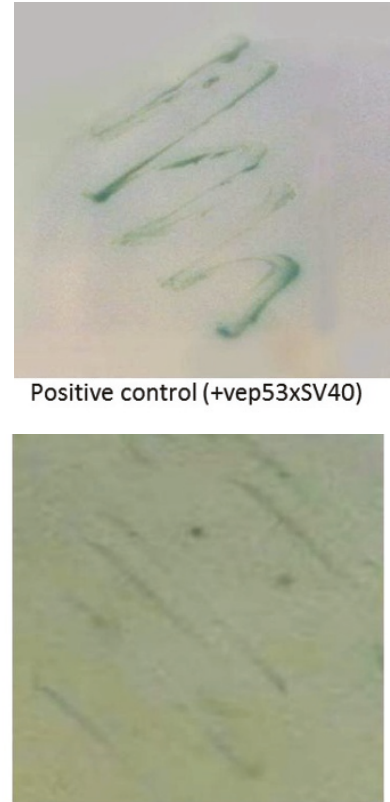

Sigma-70 factor/ x Phosphoenolpyruvate RNA polymerase carboxylase sigma factor

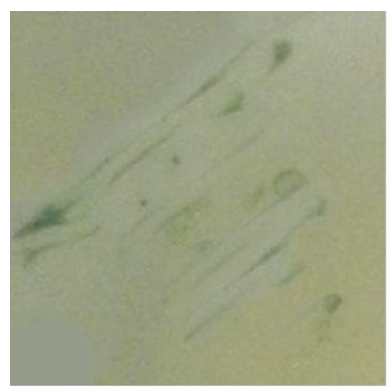

Uroporphyrinogen x Hik21 decarboxylase

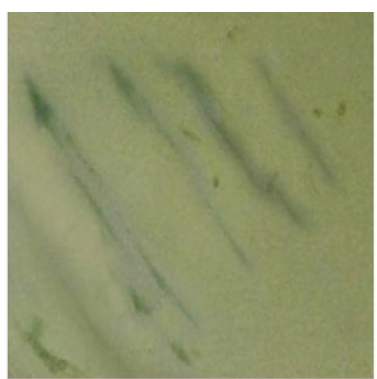

Sigma-70 factor/ x Putative transcriptional RNA polymerase activator Baf/possible sigma factor
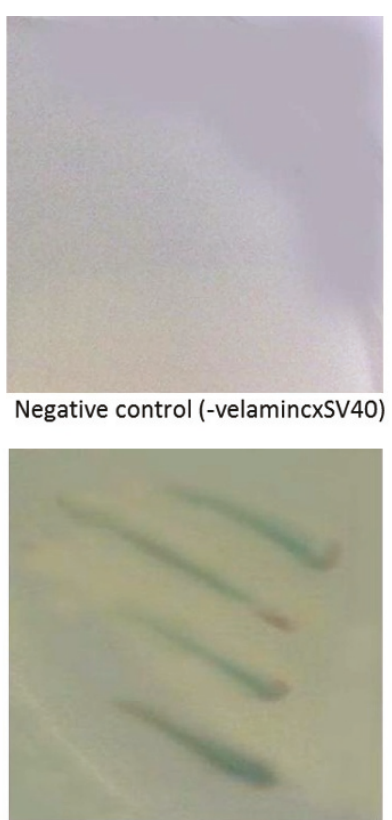

Sigma-70 factor/ $\mathrm{x}$ Light-independent RNA polymerase protochlorophyllide sigma factor reductase

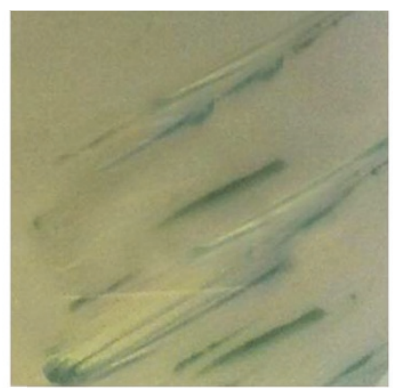

Respone regulator X Elongation (PleD)

Figure 12 Positive results of the designated protein-protein interactions using a yeast two hybrid system.

involved in several processes, including the following: (i) protoporphyrin biosynthesis, which is an intermediate in chlorophyll biosynthesis [13], (ii) the signaling of the plastid to the nucleus [14], and (iii) regulation by thioredoxin [15].
Photosynthesis, which has been suggested to be maintained in cyanobacteria during low-temperature stress $[4,16,17]$, has been shown to relate to many cell processes, including the oxidative stress response, nitrogen and ammonia assimilation, and the regulation of stress- 


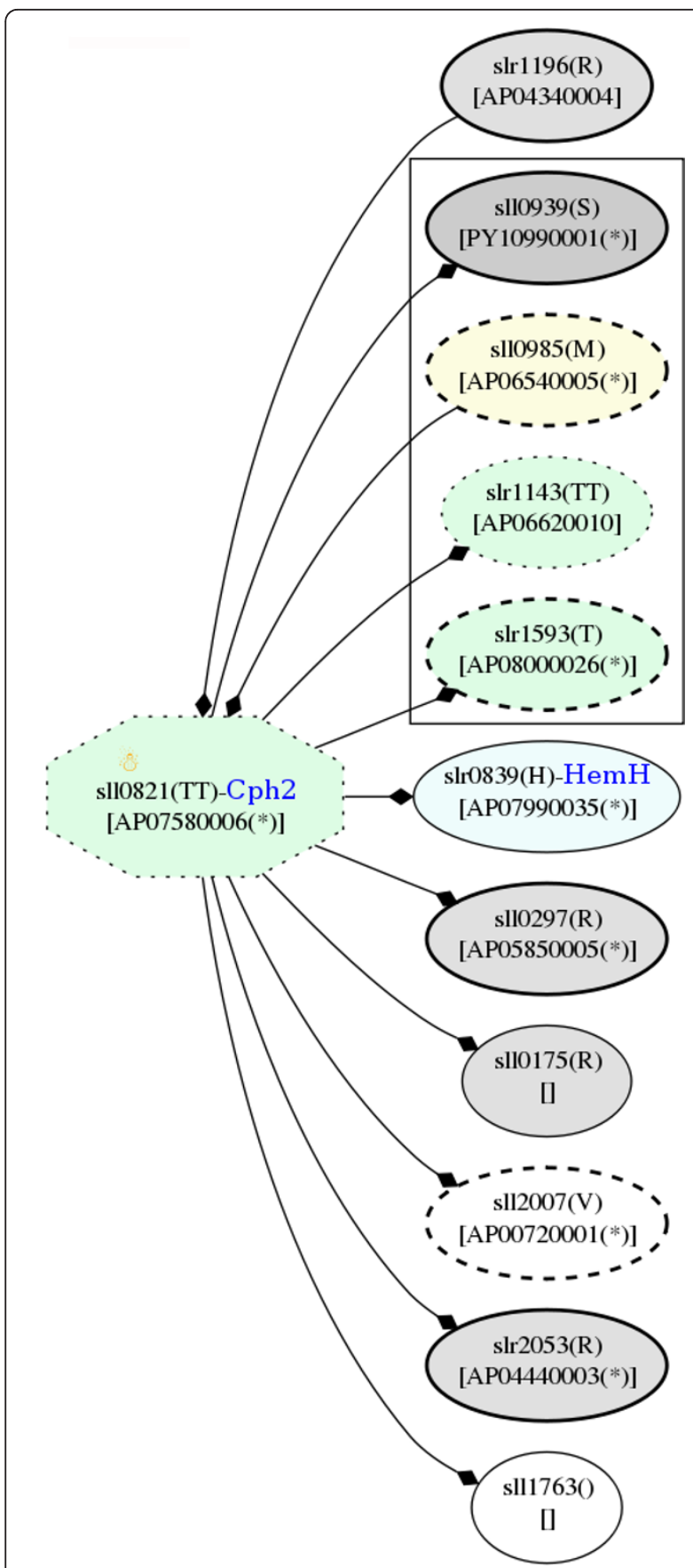

Figure 13 Snapshots of AP07580006, two component response regulator, in the potential protein-protein interaction network in Spirulina in response to the temperature stresses. The networks were constructed based on the data from Cyanobase.

related proteins. For example, SAH hydrolase, a common temperature stress protein, is not only involved in oxidative stress, but is also associated with photosynthesis during the methyl-group donation process [18]. Moreover, the association with nitrogen and ammonia

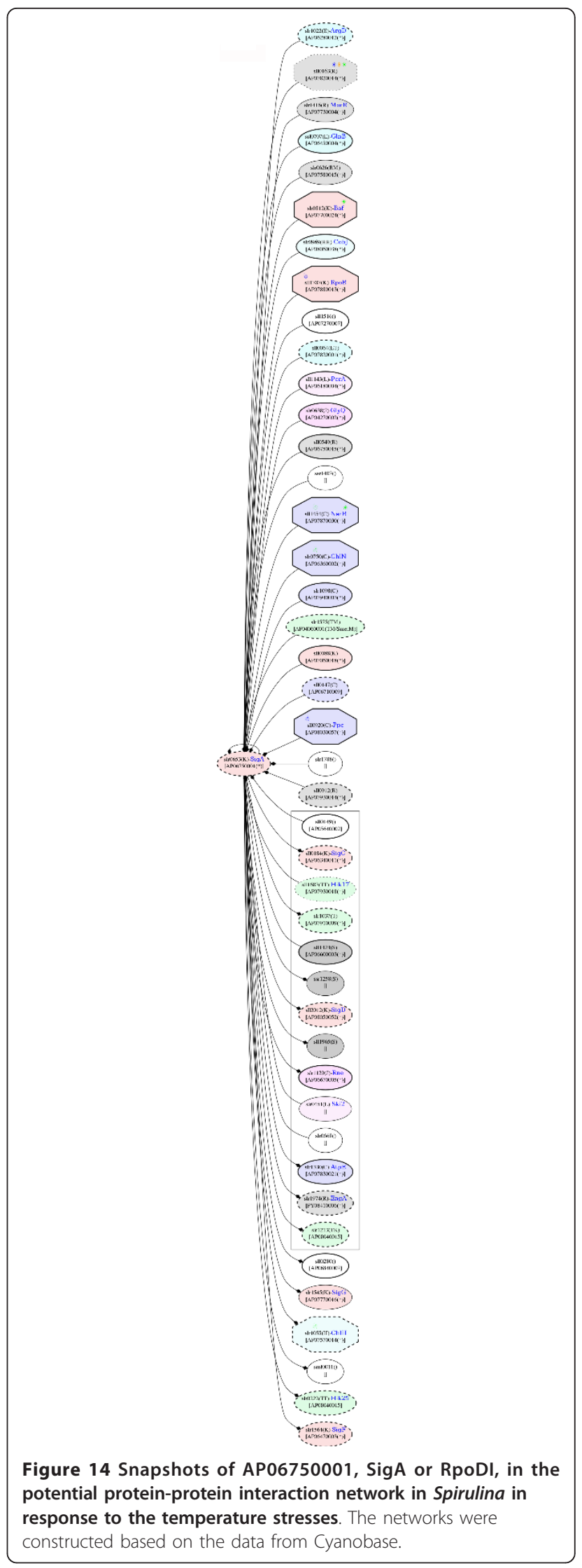




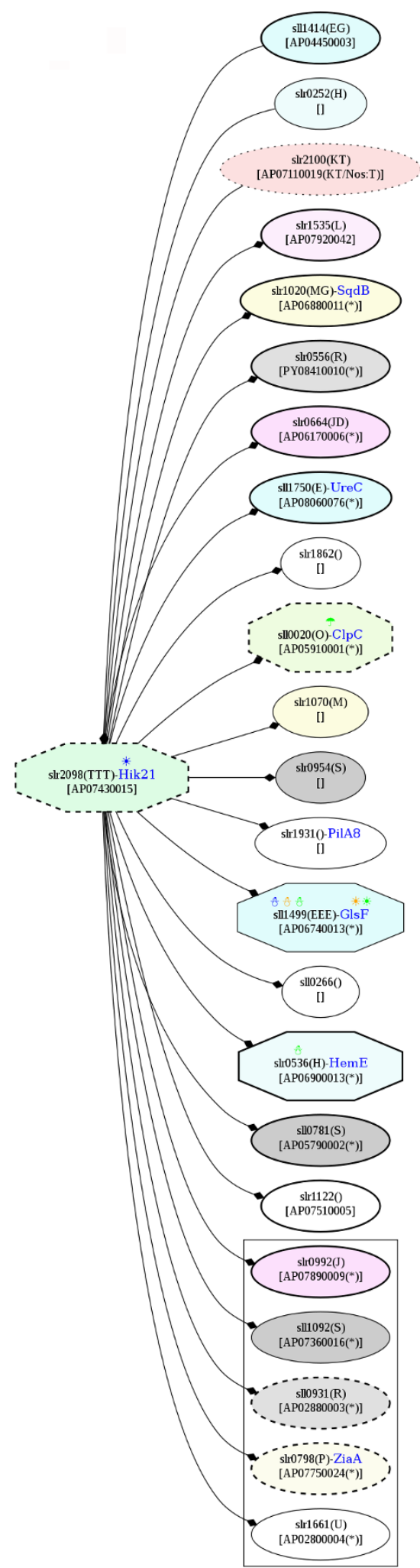

Figure 15 Snapshots of AP07430015, Hik21, in the potential protein-protein interaction network in Spirulina in response to the temperature stresses. The networks were constructed based on the data from Cyanobase. assimilation and with stress-related protein regulation occurs via RpoD [19] and NADH dehydrogenase, respectively [20]. Su et al. reported that nitrogen and ammonia assimilation is tightly coordinated with photosynthesis [21], and Sakamoto and Bryant reported that low temperature causes nitrogen limitation [22]. Accordingly, the proteomic analyses of the response of Spirulina to low-temperature stress using the two approaches indicated that many proteins involved in nitrogen and ammonia assimilation were differentially expressed [4].

Another two up-regulated photosynthetic proteins, Rubisco and CcmM, were associated via $\mathrm{CcmN}$ and glycosyl transferase (Glpx), which was also detected as upregulated protein under the low-temperature condition [Additional file 6 Table S4a]. However, the GlpX that was detected as an up-regulated protein in the present study was not the one encoded by the gene (AP07710045 or slr1125) shown in the potential PPI [Additional file 10 Figure S1b]. The Rubisco small subunit was found to be up-regulated in a moss, Physcomitrella patens, in response to abscisic acid [23]. Furthermore, Rubisco was interacted with a signaling protein, Hik23, in the PPI network. Recently, Pena et al reported that $\mathrm{CcmM}, \mathrm{CcmN}$ and $\mathrm{CcmA}$ physically interact with Rubisco in the $\beta$-carboxysome of a cyanobacteria, Methanosarcina thermophila, to maintain its oxidizing interior by preventing the entry of thioredoxin and other endogenous reducing agents [24]. This data suggests that in response to low-temperature stress, a carbon dioxide concentrating mechanism was also involved, which might involve the signaling of Hik23 via the Rubisco small subunit.

\section{High-temperature responsive proteins and their potential PPI}

PPI revealed that a high-temperature responsive signaling protein, AP06710002 or Hik13 interacts with the NarLfamily response regulator, which involves in nitrogen and ammonia assimilation (Figure 16). Although the NarLfamily response regulator was not detected in our study, the elevated level of Hik13 also highlights the association of temperature stress and nitrogen and ammonia assimilation. In addition, an up-regulated common temperature stress protein, DEAD/DEAH box helicase, and a downregulated cold-responsive protein, D-3-phosphoglycerate dehydrogenase (SerA), which were identified in our study [Additional file 7 Table S4b], also showed potential interactions with Hik13 (Figure 16).

According to the potential PPI network, another heatresponsive signaling protein, AP06460007 or Hik28, was revealed to have indirect association with AP07540011 or slr0687 or PleD, a down-regulated protein detected under the heat stress condition only (Figure 17). PleD 

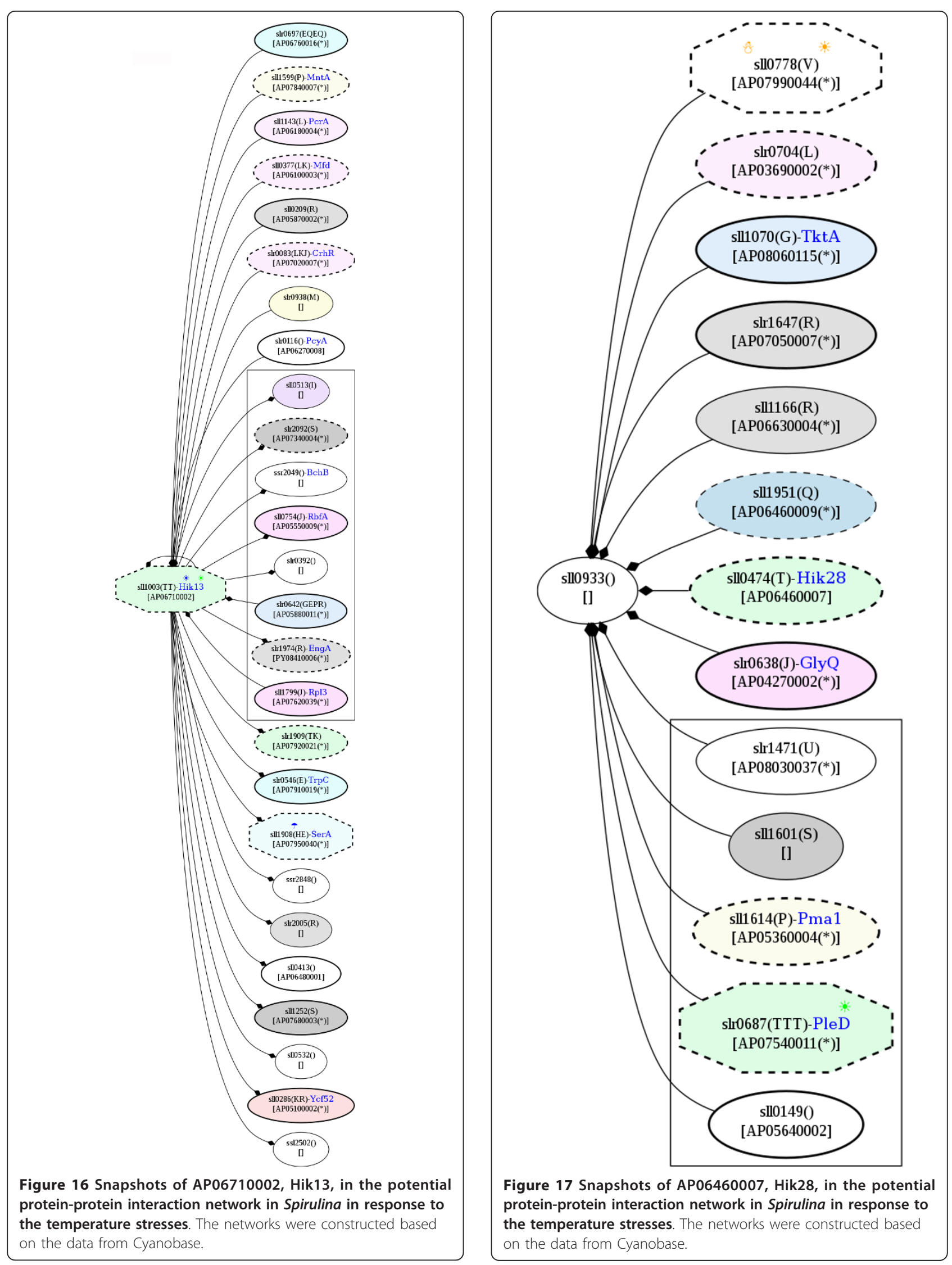
was found to interact with elongation factor EfTu and GltB or GlsF, which are classified as cold-responsive and common temperature stress proteins, respectively (Figure 18). Moreover, a pair of signaling proteins, AP06360005 or Hik15 and AP07650006 or Hik19, represents direct associations in the PPI network (Figure 19). These interactions among proteins indicate the crosstalk of proteins under temperature stress.

\section{Proteins in common between the two temperatures and their potential PPI}

According to the potential PPI network, a signaling protein, AP04840005 has no potential interaction, whereas AP07670017 interacts with a cold-responsive protein, NADH dehydrogenase, as well as others, e.g., the cell division proteins (FtsZ) and PsaL (Figure 20). As mentioned above, Ndh was detected as an up-regulated cold-responsive protein; however, this NADH dehydrogenase $(\mathrm{NdbC})$ is not encoded by the same gene as the previously discussed protein. Moreover, it is noteworthy that GltB interacted with the cut-vertex protein, two component system AP07430015 (Hik21), in the potential PPI network (Figure 15).

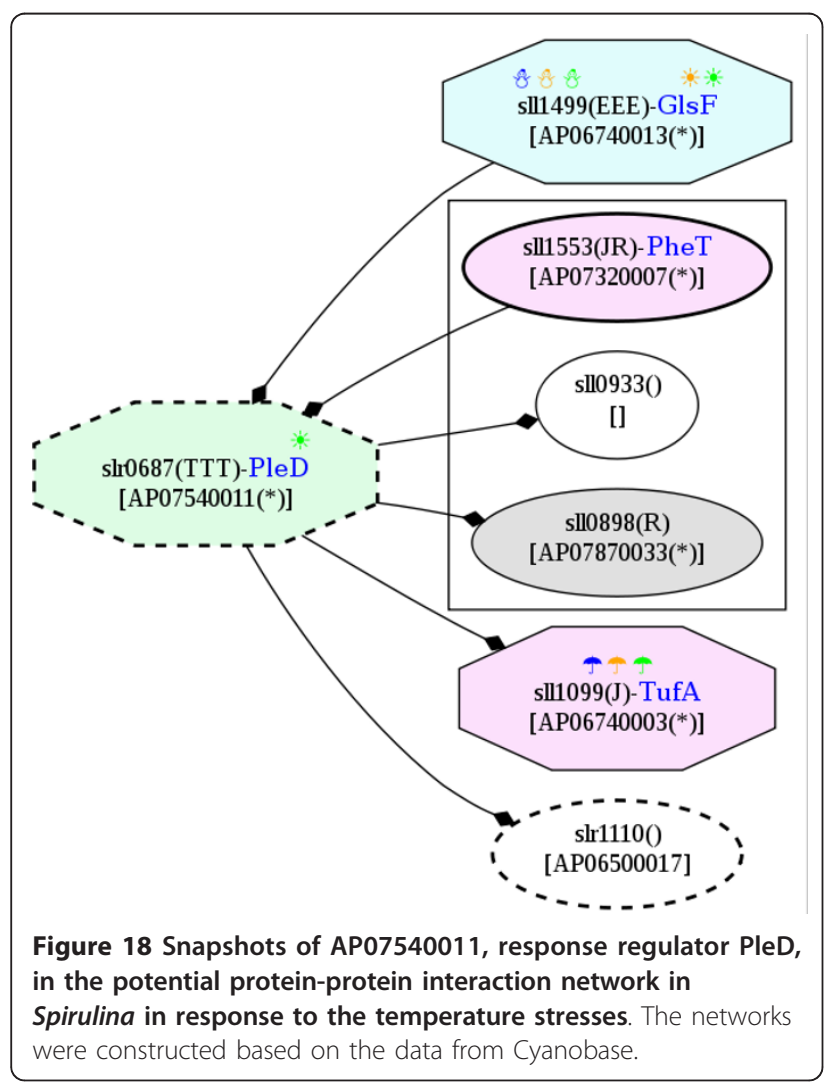

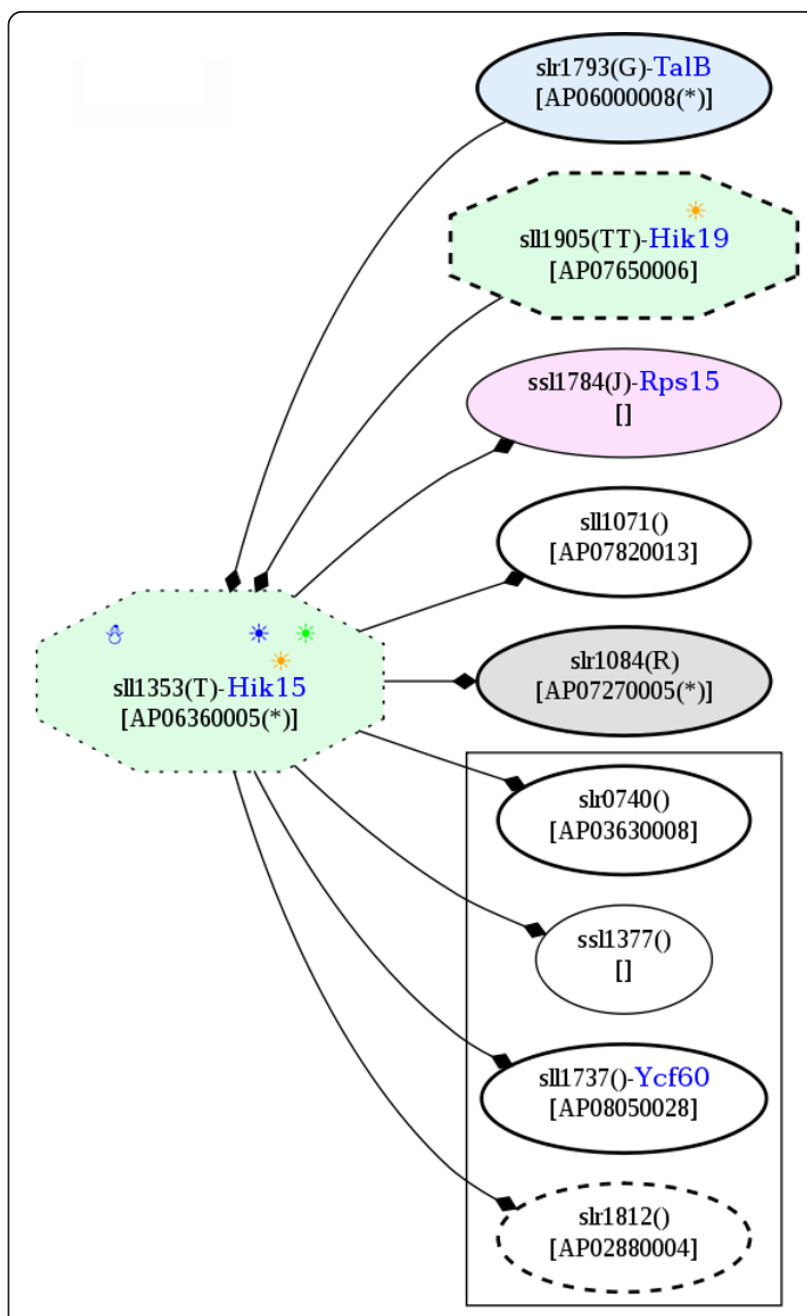

Figure 19 Snapshots of AP06360005, Hik15, in the potential protein-protein interaction network in Spirulina in response to the temperature stresses. The networks were constructed based on the data from Cyanobase.

In term of transcriptional analysis, it should be highlighted that the regulation of common temperature stress proteins were regulated at the transcriptional level.

PPI analysis by using yeast two hybrid system ( $\mathrm{Y} 2 \mathrm{H})$

The evidence of physical protein-protein interaction obtained by using $\mathrm{Y} 2 \mathrm{H}$ suggests that the potential PPI network constructed by using bioinformatics approach gives a quite reliable prediction for the analysis of specificity and cross-talk of signaling components.

\section{Conclusion}

According to the data obtained in our studies, in addition to of signal transduction systems, chaperones and DNA damage/DNA repairing proteins, nitrogen and 


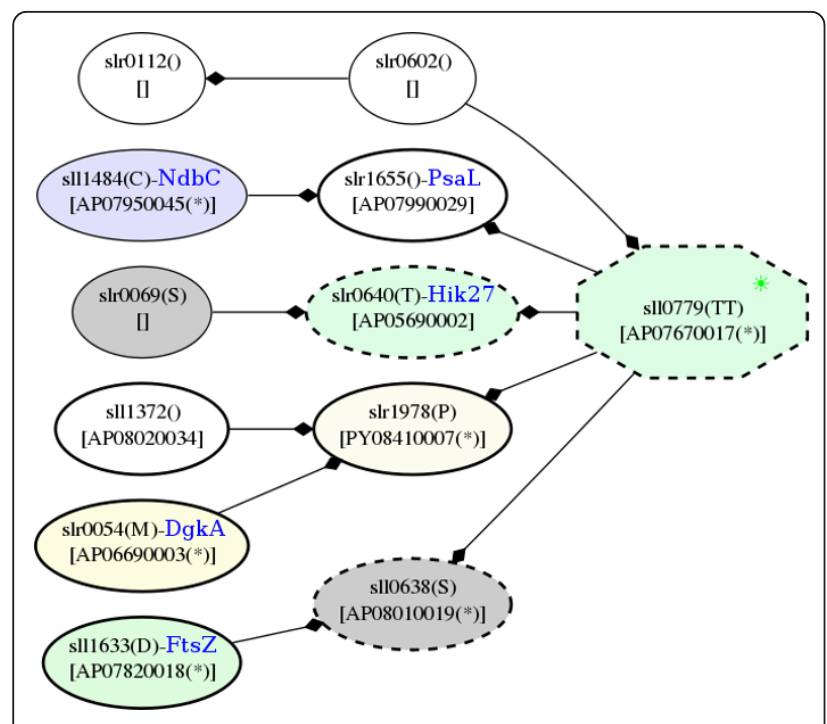

Figure 20 Snapshots of AP07670017, two component sensor histidine kinase, in the potential protein-protein interaction network in Spirulina in response to the temperature stresses. The networks were constructed based on the data from Cyanobase. ammonia assimilation is the common mechanism found after low- and high-temperature stress exposure in Spirulina. This result shows the linkage of temperature stress with nitrogen and ammonia assimilation. The results also indicate that low-temperature stress is tightly linked with oxidative stress and photosynthesis, as has been reported by several research groups, whereas no specific mechanism is revealed in the case of the high-temperature stress response. The differences in the response mechanisms of the cells to the two abiotic stress conditions are expected because of the different effects the two conditions have on the cells. Temperature reduction leads to impaired protein biosynthesis, stabilization of DNA and RNA secondary structures, and, particularly, to a reduction in membrane fluidity [25], whereas high-temperature stresses are known to cause protein aggregation and denaturation.

In the previous study, we reported evidence of crosstalk among three subcellular fractions, the plasma membrane, soluble and thylakoid membrane protein fractions, by considering each stress in isolation from other

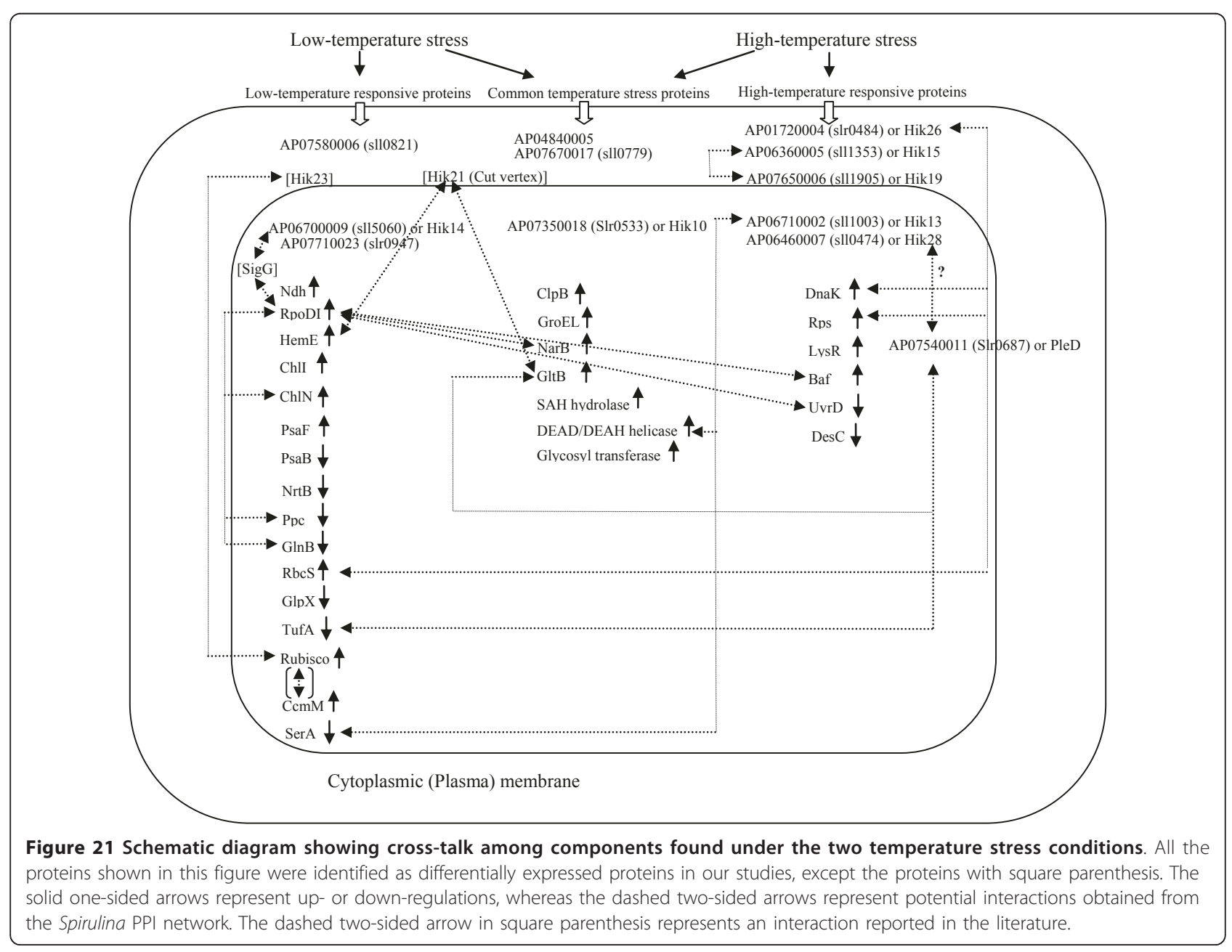


stresses $[4,5]$. However, in the present study, when the potential PPI network is analyzed in coordination with the differentially expressed proteins that were identified in each temperature stress condition (Figure 21), the cross-talk of signaling pathways are observed. As shown in Figure 21, the two temperature stresses share common elements that are potential points of cross-talk. For example, Hik14 indirectly interacted with RpoDI or SigA, and RpoDI shows potential interactions with several differentially expressed proteins identified under low-temperature, high-temperature and both conditions. Further evidence of common elements is the detection of a certain group of proteins under many types of stress, e.g., proteins related to oxidative stress were identified under oxidative stress [26], low-temperature stress [4], salt stress and hyperosmotic stress [27,28]. A possible reason for this might be the requirement of the same protective action or, at least, some common elements under these stress conditions. Moreover, in this study, we found three signaling proteins (two in the plasma membrane and one in the soluble fraction) that were triggered by the two different temperature stresses (Figure 21), supporting the common element sharing hypothesis mentioned above.

In spite of overlapping response mechanisms, a specific response was also observed in case of the low-temperature stress exposure. We identified many differentially expressed photosynthetic related proteins under this particular condition. Induction of the appropriate response that would be suited to the stress condition and avoidance of the high energy cost might be the reasons for this specific response.

In the present study, protein-protein interactions, which are well known to be tightly link with signal transduction cascades [29], were constructed by mapping the differentially expressed proteins of Spirulina under two types of stress, using two proteomic approaches, onto the PPI network of Synechocystis, which has been constructed using the results obtained from $\mathrm{Y} 2 \mathrm{H}$ analyses of Synechocystis. The $\mathrm{Y} 2 \mathrm{H}$ data obtained in this study suggest that the potential PPI network gives quite reliable potential interactions for Spirulina. Where proteome analyses of knockout mutants have not been carried out to directly examine for specificity or cross-talk of signaling components due to the lack of a stable transformation system in Spirulina, the bioinformatics approach employed in this study helps in analysis of phenomena.

\section{Additional material}

Additional file 1: Table S1a. A result file of soluble fraction obtained by using ProteinPilot ${ }^{\mathrm{TM}^{\mathrm{TM}}}$ software.
Additional file 2: Table S1b. A result file of plasma membrane fraction obtained by using ProteinPilot ${ }^{\mathrm{TM}^{\mathrm{TM}}}$ software.

Additional file 3: Table S1c. A result file of thylakoid membrane fraction obtained by using ProteinPilot ${ }^{\mathrm{TM}^{\mathrm{TM}}}$ software.

Additional file 4: Table S2. Details on primers and conditions used for transcriptional analysis by RT-PCR.

Additional file 5: Table S3. List of differentially expressed proteins (after having been filtering by statistical criteria mentioned in Material \& Methods) detected by the two techniques under low-temperature and high temperature stresses. The column names, coldLC, cold2D and heat2D, represent the conditions and techniques, whereas the fractions where the proteins were detected are listed by abbreviation $\mathrm{S}, \mathrm{P}$ and $\mathrm{T}$ for soluble, plasma membrane and thylakoid membrane fractions, respectively.

Additional file 6: Table S4a. List of differentially expressed proteins (after having been filtering by statistical criteria mentioned in Material \& Methods) detected by the two techniques under low-temperature stress only. The column names, coldLC, cold2D and heat2D, represent the conditions and techniques, whereas the fractions where the proteins were detected are listed by abbreviation S, P and T for soluble, plasma membrane and thylakoid membrane fractions, respectively.

Additional file 7: Table S4b. List of differentially expressed proteins (after having been filtering by statistical criteria mentioned in Material \& Methods) under high-temperature stress only. The column names, coldLC, cold2D and heat2D, represent the conditions and techniques, whereas the fractions where the proteins were detected are listed by abbreviation S, P and T for soluble, plasma membrane and thylakoid membrane fractions, respectively.

Additional file 8: Table S4c. List of differentially expressed proteins (after having been filtering by statistical criteria mentioned in Material \& Methods) detected by the two techniques under both temperature stresses. The column names, coldLC, cold2D and heat2D, represent the conditions and techniques, whereas the fractions where the proteins were detected are listed by abbreviation $\mathrm{S}, \mathrm{P}$ and $\mathrm{T}$ for soluble, plasma membrane and thylakoid membrane fractions, respectively.

Additional file 9: Figure S1a. Potential protein-protein interaction (PPI) network under the two temperature stress conditions of the three subcellular fractions. (a) PPI of soluble fraction in response to lowtemperature stress analyzed by 2D-DIGE and LC-MS/MS.

Additional file 10: Figure S1b. Potential protein-protein interaction (PPI) network under the two temperature stress conditions of the three subcellular fractions. (b) PPI of soluble fraction in response to lowtemperature stress analyzed by LC-MS/MS.

Additional file 11: Figure S1c. Potential protein-protein interaction (PPI) network under the two temperature stress conditions of the three subcellular fractions. (c) PPI of plasma membrane fraction in response to low-temperature stress analyzed by 2D-DIGE and LC-MS/MS.

Additional file 12: Figure S1d. Potential protein-protein interaction (PPI) network under the two temperature stress conditions of the three subcellular fractions. (d) PPI of plasma membrane fraction in response to low-temperature stress analyzed by LC-MS/MS.

Additional file 13: Figure S1e. Potential protein-protein interaction (PPI) network under the two temperature stress conditions of the three subcellular fractions. (e) PPI of thylakoid membrane fraction in response to low-temperature stress analyzed by 2D-DIGE and LC-MS/MS.

Additional file 14: Figure S1f. Potential protein-protein interaction (PPI) network under the two temperature stress conditions of the three subcellular fractions. (f) PPI of thylakoid membrane fraction in response to low-temperature stress analyzed by LC-MS/MS.

Additional file 15: Figure S1g. Potential protein-protein interaction (PPI) network under the two temperature stress conditions of the three subcellular fractions. (g) PPI of soluble fraction in response to hightemperature stress analyzed by 2D-DIGE.

Additional file 16: Figure S1h. Potential protein-protein interaction (PPI) network under the two temperature stress conditions of the three 
subcellular fractions. (h) PPI of plasma membrane fraction in response to high-temperature stress analyzed by 2D-DIGE.

Additional file 17: Figure S1i. Potential protein-protein interaction (PPI) network under the two temperature stress conditions of the three subcellular fractions. (i) PPI of thylakoid membrane fraction in response to high-temperature stress analyzed by 2D-DIGE.

Additional file 18: Figure S2. Transcriptional analyses of some differentially expressed proteins using RT-PCR (top panel) and protein expression levels (bottom panel) of the designated open-reading frames subjected to the transcriptional analysis. (Note: In case of proteins detected by LC-MS/MS technique, the protein expression levels at 45, 90 and $180 \mathrm{~min}$ compared to that of at 0 min are 115:114, 116:114 and 117:114 ratios of iTRAQ, respectively. In case of proteins detected by 2DDIGE, the protein expression levels at 0, 45, 90 and $180 \mathrm{~min}$ are log-value of the protein-spot density at the designated time period compared to that of at 0 min.).

Additional file 19: Table S5. List of differentially expressed proteins (after having been filtering by statistical criteria mentioned in Material \& Methods) detected by LC-MS/MS technique under low-temperature stress only. The fractions where the proteins were detected are listed by abbreviation S, P and T for soluble, plasma membrane and thylakoid membrane fractions, respectively, whereas the column names, Cluster no. _S, Cluster no._P and Cluster no._T represent the protein-expressionpattern cluster number of the designated protein found in soluble, plasma membrane and thylakoid membrane fractions, respectively.

\section{Acknowledgements}

This research was funded by a grant from the National Center for Genetic Engineering and Biotechnology (BIOTEC), Bangkok, Thailand. The work on the iTRAQ-multidimensional liquid chromatography and tandem mass spectrometry was in collaboration with Bioprocessing Technology Institute, Singapore.

\section{Author details}

'BEC Unit, National Center for Genetic Engineering and Biotechnology, 49 Soi Theintalay 25, Thakham, Bangkhuntien, Bangkok, 10150, Thailand. ${ }^{2}$ School of Bioresources and Technology, King Mongkut's University of Technology Thonburi, 49 Soi Theintalay 25, Thakham, Bangkhuntien, Bangkok, 10150, Thailand. ${ }^{3}$ Pilot Plant Development and Training Institute, King Mongkut's University of Technology Thonburi, 49 Soi Theintalay 25, Thakham, Bangkhuntien, Bangkok, 10150, Thailand.

\section{Authors' contributions}

PK carried out the transcriptional analysis by RT-PCR and participated in the protein-protein interaction studies by yeast two hybrid system. JS carried out the protein clustering and the protein-protein interaction network construction. MS carried out the protein analysis by using liquid chromatography-tandem mass spectrometry and participated in the file conversion from (*.wiff) to ${ }^{*}$.mzXML and then to ${ }^{*}$.mgf files. RY carried out the culturing of Spirulina and membrane preparation. PP participated in the protein-protein interaction studies by yeast two hybrid system. WJ participated in the DNA-probe design for transcriptional analysis. SR participated in the file conversion from (*.wiff) to *.mzXML and then to * mgf files. SC participated in the providing of genome database used for protein identification. AH conceived of the study, carried out the data interpretation and its design and coordination. All authors read and approved the final manuscript.

\section{Declaration of competing interests}

The authors declare that they have no competing interests.

Received: 7 January 2011 Accepted: 15 July 2011

Published: 15 July 2011

\section{References}

1. Wada H, Murata N: Temperature-induced changes in the fatty acid composition of the cyanobacterium, Synechocystis sp. PCC 6803. Plant Physiol 1990, 92:1062-1069.
2. Hongsthong A, Deshnium P, Paithoonrangsarid K, Cheevadhanarak S, Tanticharoen M: Differential responses of the three acyl-lipid desaturases to immediate temperature reduction occurred in two lipid membranes of Spirulina platensis strain C1. J Biosci Bioeng 2003, 96:519-524.

3. Deshnium P, Paithoonrangsarid K, Suphatrakul A, Meesapyodsuk D, Tanticharoen M, Cheevadhanarak S: Temperature-independent and -dependent expression of desaturase genes in filamentous cyanobacterium Spirulina platensis strain C1 (Arthrospira sp. PCC 99438). FEMS Microbiol Lett 2000, 184:207-213.

4. Hongsthong A, Sirijuntarut M, Prommeenate P, Lertladaluck K, Porkaew K, Cheevadhanarak S, Tanticharoen M: Proteome analysis at the subcellular level of the cyanobacterium Spirulina platensis in response to lowtemperature stress conditions. FEMS Microbiol Lett 2008, 288:92-101.

5. Hongsthong A, Sirijuntarut M, Yutthanasirikul R, Senachak J, Kurdrid P, Cheevadhanarak S, Tanticharoen M: Subcellular proteomic characterization of the high-temperature stress response of the cyanobacterium Spirulina platensis. Proteome Sci 2009, 7.

6. Richmond A: Microalgae of economic potential. In CRC Handbook of Microalgal Mass Culture. Edited by: Richmond A. Boca Raton, FL.: CRC Press; 1986:199-244.

7. Murata N, Omata T: Isolation of cyanobacterial plasma membranes. Methods in Enzymology 1988, 167:245-251.

8. Jayapal KP, Philp RJ, Kok YJ, Yap MGS, Sherman DH, Griffin TJ, Hu WS: Uncovering genes with divergent mRNA-protein dynamics in Streptomyces coelicolor. PLoS ONE 2008, 3:e2097.

9. Jeamton W, Mungpakdee S, Sirijuntarut M, Prommeenate $P$, Cheevadhanarak S, Tanticharoen M, Hongsthong A: A combined stress response analysis of Spirulina platensis in terms of global differentially expressed proteins, and mRNA levels and stability of fatty acid biosynthesis genes. FEMS Microbiol Lett 2008, 281:121-131.

10. Martin S, Zhang Z, Martino A, Faulon JL: Boolean dyanamics of genetic regulatory networks inferred from microarray time series data. Bioinformatics 2007, 23:866-874

11. Sato S, Shimoda Y, Muaki A, Kohara M, Nakamura Y, Tabata S: A large-scale protein-protein interaction analysis in Synechocystis sp. PCC6803. DNA Res 2007, 14:207-216

12. Lacerda CMR, Choe LH, Reardon KF: Metaproteomics analysis of a bacterial community response to cadmium exposure. J Proteome Res 2007, 6:1145-1152.

13. Verdecia MA, Larkin RM, Ferrer J, Chory J, Noel JP: Structure of the magnesium chelatase cofactor GUN4 reveals a novel hand-shaped fold for porphyrin binding. PLOS Biol 2005, 3:777-789.

14. Mochizuki N, Brusslan JA, Larkin RM, Nagatani A, Chory J: Arabidopsis genomes uncoupled 5 (GUN5) mutant reveals the involvement of Mgchelatase $\mathrm{H}$ subunit in plastid-to-nucleus signal transduction. Proc Natl Acad Sci USA 2001, 98:2053-2058.

15. Ikegami A, Yoshimura N, Motohasi K, Takahashi S, Romano PGN, Hisabori T, Takamiya K, Masuda T: The CHLI1 subunit of Arabidopsis thaliana magnesim chelatase is a target protein of the chloroplast thioredoxin. $J$ Biol Chem 2007, 282:19282-19291.

16. Tewari AK, Tripathy BC: Temperature-stress-induced impairment of chlorophyll biosynthetic reactions in cucumber and wheat. Plant Physiol 1998, 117:851-858.

17. Duv D, Wanner G, Meda AR, von Wiren N, Soll J, Philippar K: PIC1, an ancient permease in Arabidopsis chloroplast, mediated iron transport. Plant Cell 2007, 19:986-1006.

18. Dayan FE, Rimando AM, Pan Z, Baerson SR, Gimsing AL, Dke SO: Sorgoleone. Phytochem 2010, 71:1032-1039.

19. Asayama M, Suzuki A, Nozawa S, Yamada A, Tanaka K, Takahashi H, Aida T, Shirai M: A new sigma factor homolog in a cyanobacterium: cloning, sequencing, and light-responsive transcripts of rpoD2 from Microcystis aeruginasa K-81. Biochem Biophys Res Commun 1997, 1351:31-36.

20. Svensson AS, Johansson Fl, Moller IM, Rasmusson AG: Cold stress decreases the capacity for respiratory NADH oxidation in potato leaves. FEBS Lett 2002, 517:79-82.

21. Su Z, Mao F, Dam P, Wu H, Olman V, Paulsen IT, Palenik B, Xu Y: Computational inference and experimental validation of the nitrogen assimilation regulatory network in cyanobacterium Synechococcus sp. WH 8102. Nucleic Acids Res 2006, 34:1050-1065.

22. Sakamoto T, Bruyant D: Growth a low temperature causes nitrogen limitation in the cyanobacterium Synechococcus sp. PCC 7002. 1998. 
23. Wang $X$, Kuang $T$, He Y: Conservation between higher plants and the moss Physcomitrella patens in response to the phytohormone abscisic acid: a proteomics analysis. BMC Plant Biol 2010, 10:1-11.

24. Pena KL, Castel SE, Araujo C, Espie GS, Kimber MS: Structural basis of the oxidative activation of the carboxysomal gamma-carboni anhydrase, CcmM. Proc Natl Acad Sci USA 2010, 107:2455-2460.

25. Wang Y, Delettre J, Guillot A, Corrieu G, Beal C: Influence of cooling temperature and duration on cold adaptation of Lactobacillus acidophilus RD758. Cryobiology 2005, 50:294-307.

26. Yan X, Zhoa C, Budin-Verneuil A, Hartke A, Rince A, Gilmore MS, Auffray $Y$, Pichereau V: The (p)ppGpp synthetase RelA contributes to stress adaptation and virulence in Enterococcius faecalis V583. Microbiol 2009, 155:3226-3237.

27. Shoumskaya MA, Paithoonrangsarid K, Kanesaki Y, Los DA, Zinchenko W, Tanticharoen M, Suzuki I, Murata N: Identfication Hik-Rre systems are involved in perception and transduction of salt signals and hyperosmotic signals but regulate the expression of individual genes to different extent in Synechocystis. J Biol Chem 2005, 280:21531-21538.

28. Paithoonrangsarid K, Shoumskaya MA, Kanesaki Y, Satoh S, Tabata S, Los DA, Zinchenko W, Hayashi H, Tanticharoen M, Suzuki I, Murata N: Five histidine kinases perceive osmotic stress and regulate distinct sets of genes in Synechocystis. J Biol Chem 2004, 279:53078-53086.

29. Gourion B, Sulser S, Frunzke J, Francez-Charlot A, Stiefel P, Pessi G, Vorholt JA, Fischer HM: The PhyR-sigma(EcfG) signalling cascade is involved in stress response and symbiotic efficiency in Bradyrhizobium japonicum. Mol Microbiol 2009, 73:291-305.

doi:10.1186/1477-5956-9-39

Cite this article as: Kurdrid et al: Comparative analysis of the Spirulina platensis subcellular proteome in response to low- and high-

temperature stresses: uncovering cross-talk of signaling components. Proteome Science 2011 9:39.

\section{Submit your next manuscript to BioMed Central and take full advantage of:}

- Convenient online submission

- Thorough peer review

- No space constraints or color figure charges

- Immediate publication on acceptance

- Inclusion in PubMed, CAS, Scopus and Google Scholar

- Research which is freely available for redistribution

Submit your manuscript at www.biomedcentral.com/submit 